\title{
QUAL UNIVERSIDADE PARA QUAL SOCIEDADE?
}

\author{
A. B. ÉSTHER \\ Universidade Federal de Juiz de Fora \\ angelo.esther@ufjf.edu.br
}

Artigo submetido em agosto/2016 e aceito em setembro/2016

DOI: $10.15628 /$ holos.2016.4971

\section{RESUMO}

A universidade é uma das instituições mais duradouras da história, embora ela venha se transformando ao longo dos séculos, desde sua criação original na Europa, nos idos do século XI. A despeito de sua longevidade, nem sempre sua existência foi inquestionável, pois, em diversos momentos, as sociedades, os governos e os Estados colocaram em xeque a necessidade de sua permanência e de sua forma organizativa. Neste sentido, entendemos que as políticas educacionais compreendem parte do repertório de iniciativas e de regulações que visam a articulação entre aquelas esferas, sobretudo quando pensamos acerca de qual é a concepção que se tem acerca da educação superior e suas finalidades sociais e econômicas. Para além dos discursos, mas, necessariamente, a eles associados, decisões concretas e pragmáticas precisam ser tomadas, como, por exemplo, prioridades quanto à distribuição de recursos públicos. Assim, procura-se problematizar a universidade tendo em vista sua articulação com o Estado, com o governo e com a sociedade, tendo em conta as diversas demandas, expectativas, necessidades dos diversos atores sociais.

PALAVRAS-CHAVE: universidade, modelo de sociedade, política pública, política de educação, educação superior

\section{WHICH UNIVERSITY FOR WHICH SOCIETY?}

\section{ABSTRACT}

The university is one of the institutions most lasting of history, although it will be turning over the centuries, since their original creation in Europe back in the 11th century. Despite his longevity, not always its existence was unquestioned, as, at various times, companies, governments and the State have put into question the need for its permanence and its organizational form. In this sense, we understand that the educational policies comprise part of the repertoire of initiatives and regulations that aim to link between those spheres, especially when we think about what is the conception about higher education and its purposes. In addition practical decisions and pragmatic need to be taken, as, for example, priorities as to the distribution of public resources. Thus, the aim is to problematize the university with a view to its articulation with the State, with the government and society, taking into account the various demands, expectations and needs of various social actors.

KEYWORDS: university, model of society, public policy, education policy, higher education. 


\section{INTRODUÇÃO}

A universidade é uma das instituições mais duradouras da história, embora ela venha se transformando ao longo dos séculos, desde sua criação original na Europa, nos idos do século XI. A despeito de sua longevidade, nem sempre sua existência foi inquestionável, pois, em diversos momentos, as sociedades, os governos e os Estados colocaram em xeque a necessidade de sua permanência e de sua forma organizativa. Ainda assim, ela sobreviveu. Por outro lado, a universidade da forma como conhecemos é relativamente recente, pois ela se institucionaliza apenas no século XVI. Desde então, tal como em sua fase medieval, ela não ficou imune a críticas e crises. Dentre elas, ficaram célebres aquelas apontadas por Boaventura Santos: as crises de hegemonia, de legitimidade e institucional (SANTOS, 1995; 2004), como veremos adiante.

No caso brasileiro, em particular, a trajetória da universidade pode ser caracterizada por uma "eterna crise" (TORGAL, ÉSTHER, 2014), mesmo na fase anterior à sua criação oficial no século XX. Nesta trajetória, a relação da universidade com a sociedade, com o Estado e com os governos tem sido marcada por tensões e contradições, envolvendo posições e concepções conflitantes, especialmente em relação a seu papel, finalidades e identidade. Tal situação implica um forte jogo político, que tende a culminar em políticas e práticas institucionalizadas, mesmo que não consensuais.

Neste sentido, entendemos que as políticas educacionais compreendem parte do repertório de iniciativas e de regulações que visam a articulação entre aquelas esferas, sobretudo quando pensamos acerca de qual é a concepção que se tem acerca da educação superior e suas finalidades sociais e econômicas. Para além dos discursos, mas, necessariamente, a eles associados, decisões concretas e pragmáticas precisam ser tomadas, como, por exemplo, prioridades quanto à distribuição de recursos públicos. Assim, se a educação é considerada elemento ou "fator" de desenvolvimento econômico e social, a eficiência e a eficácia da administração política passa a ser uma questão igualmente fundamental.

O artigo tem como objetivo discutir os rumos da universidade pública brasileira notadamente a federal - no que diz respeito à sua identidade e modelos de governança, a partir de uma perspectiva histórica, com vistas a analisar suas possibilidades futuras. Neste aspecto, procura-se problematizar a universidade tendo em vista sua articulação com o Estado, com o governo e com a sociedade, tendo em conta as diversas demandas, expectativas, necessidades dos diversos atores sociais. Isto implica, pelo menos em parte, a articulação com as esferas da educação superior - no que diz respeito, especialmente, às suas finalidades prescritas -, da produção - tendo em vista a crescente demanda por conhecimento como "fator de competição" - e da própria economia - que vem "exigindo" da universidade o desempenho do papel de agente econômico.

\section{AS CONCEPÇÕES DE UNIVERSIDADE: MODELOS E CRISES}

A despeito de sua antiguidade, a universidade possui características e configurações distintas ao longo de sua existência, cujas variações expressam, de forma dialética, as transformações da sociedade como um todo. Neste sentido, Drèze e Debelle (1983) entendem a instituição universitária segundo cinco pontos de vista, que denominam "concepções da 
universidade": centro de educação, comunidade de pesquisadores, núcleo de progresso, modelo intelectual e fator de produção. As três primeiras concepções compõem o que os autores chamam de "a universidade do espírito", e que dizem respeito aos ideais mais tradicionais da universidade, sendo representadas pela universidade inglesa, pela alemã e pela norte-americana, respectivamente. As duas últimas concepções são agrupadas sob o rótulo "a universidade do poder", concernentes à universidade francesa e à soviética. As principais características identificadas pelos autores, observadas no Quadro 1, referem-se à forma como os autores percebem as universidades.

Cada concepção retrata a universidade de acordo com as sociedades em que foram iniciadas e com a interpretação da realidade de sua época. Assim, a universidade inglesa visava à difusão e à extensão do saber universal. Segundo Newman, não haveria razão para que ela tivesse estudantes se ela fosse apenas um lugar para descoberta científica e filosófica, ou seja, consagrada à pesquisa. Sua concepção, compatível com sua época, era a de que o homem buscava naturalmente o saber e que este deveria ser ensinado nas universidades. No entanto, tal saber não era exclusivamente profissional (DRÈZE \& DEBELLE, 1983).

A universidade alemã, inspirada na universidade de Huboldt, tem como representante mais contemporâneo Karl Jaspers, o qual parte do princípio de que a humanidade aspira à verdade, e daí a necessidade de se criar uma comunidade de pesquisadores e estudantes. Segundo essa premissa, a universidade deve existir com base em dois princípios: a unidade do saber; e a unidade da pesquisa e do ensino (que, para Jaspers, significa iniciação à pesquisa). Assim, para se descobrir a verdade, é necessária a liberdade acadêmica - ou seja, não deve haver censura intelectual (DRÈZE \& DEBELLE, 1983).

$\mathrm{Na}$ concepção de Whitehead, a universidade americana deve ter a capacidade de influenciar o lugar público e de ser por este influenciado, de modo que se obtenha o progresso da sociedade. A ênfase no progresso é menos desinteressada do que a aspiração ao saber e à verdade, mas a cultura e a ciência deveriam desembocar na ação; ou seja, serem úteis. Portanto, a pesquisa e a educação são primordiais para o progresso, devendo-se aliar a imaginação à experiência e o entusiasmo criador à ciência adquirida para uma reflexão inventiva sobre as formas de saber. Assim, "trata-se [...] de impregnar a execução dessa dupla tarefa de um espírito inventivo, de orientar os homens que consagram a ela para a criação e o progresso; isso é próprio da universidade" (DRÈZE \& DEBELLE, 1983, p. 67).

A universidade francesa, por sua vez, não possui um autor específico de referência, sendo necessário remontar a Napoleão, por sua considerável influência, a despeito das diversas reformas educacionais que ocorreram ao longo dos séculos. Napoleão possuía uma concepção totalitária do poder segundo a qual a universidade era organizada. Assim, é a finalidade sociopolítica da instrução que define a ideia napoleônica da universidade. Em outras palavras, "serviço público do Estado, a universidade imperial é ideologicamente subjugada ao poder e se vê assumir uma função geral de 'conservação da ordem social' pela difusão de uma doutrina comum" (DRÈZE \& DEBELLE, 1983 , p. 86), por meio da organização de professores a serviço do imperador, que asseguravam basicamente o ensino profissional (DRÈZE \& DEBELLE, 1983). 
Quadro 1 - Concepções da universidade, segundo Drèze e Debelle

\begin{tabular}{|c|c|c|c|c|c|}
\hline & \multicolumn{3}{|c|}{ A universidade do Espírito } & \multicolumn{2}{|c|}{ A universidade do Poder } \\
\hline & $\begin{array}{c}\text { I } \\
\text { Um centro de } \\
\text { educação }\end{array}$ & $\begin{array}{c}\text { II } \\
\text { Uma } \\
\text { comunidade de } \\
\text { pesquisadores }\end{array}$ & $\begin{array}{c}\text { III } \\
\text { Um núcleo de } \\
\text { progresso }\end{array}$ & $\begin{array}{c}\text { IV } \\
\text { Um modelo } \\
\text { intelectual }\end{array}$ & $\begin{array}{c}\text { V } \\
\text { Um fator de } \\
\text { produção }\end{array}$ \\
\hline $\begin{array}{l}\text { Influência } \\
\text { principal }\end{array}$ & J. H. Newman & K. Jaspers & A. N. Whitehead & Napoleão & $\begin{array}{c}\text { Conselho dos } \\
\text { Ministros da } \\
\text { URSS }\end{array}$ \\
\hline Finalidade & $\begin{array}{c}\text { Aspiração do } \\
\text { indivíduo ao saber }\end{array}$ & $\begin{array}{c}\text { Aspiração da } \\
\text { humanidade à } \\
\text { verdade }\end{array}$ & $\begin{array}{c}\text { Aspiração da } \\
\text { sociedade ao } \\
\text { progresso } \\
\end{array}$ & $\begin{array}{c}\text { Estabilidade } \\
\text { política do } \\
\text { Estado } \\
\end{array}$ & $\begin{array}{l}\text { Edificação da } \\
\text { sociedade } \\
\text { comunista } \\
\end{array}$ \\
\hline $\begin{array}{c}\text { Concepção } \\
\text { geral }\end{array}$ & $\begin{array}{l}\text { Uma educação } \\
\text { geral e liberal por } \\
\text { intermédio do } \\
\text { saber universal }\end{array}$ & $\begin{array}{c}\text { A unidade da } \\
\text { pesquisa e do } \\
\text { ensino no centro } \\
\text { do universo das } \\
\text { ciências }\end{array}$ & $\begin{array}{c}\text { A simbiose da } \\
\text { pesquisa e do } \\
\text { ensino a serviço } \\
\text { da imaginação } \\
\text { criadora }\end{array}$ & $\begin{array}{l}\text { Um ensino } \\
\text { profissional } \\
\text { uniforme, } \\
\text { confiado a um } \\
\text { grupo } \\
\text { profissional } \\
\end{array}$ & $\begin{array}{l}\text { Um instrumento } \\
\text { funcional de } \\
\text { formação } \\
\text { profissional e } \\
\text { política }\end{array}$ \\
\hline $\begin{array}{l}\text { Princípios de } \\
\text { organização }\end{array}$ & $\begin{array}{l}\text { Uma pedagogia } \\
\text { do } \\
\text { desenvolvimento } \\
\text { intelectual; } \\
\text { internato e } \\
\text { "tutores" }\end{array}$ & $\begin{array}{c}\text { Uma sã } \\
\text { organização da } \\
\text { faculdade; } \\
\text { liberdade } \\
\text { acadêmica }\end{array}$ & $\begin{array}{l}\text { Um corpo } \\
\text { docente } \\
\text { criador; os } \\
\text { estudantes } \\
\text { capazes de } \\
\text { aplicar alguns } \\
\text { princípios gerais }\end{array}$ & $\begin{array}{l}\text { Uma hierarquia } \\
\text { administrativa; } \\
\text { programas } \\
\text { uniformes }\end{array}$ & $\begin{array}{c}\text { Uma } \\
\text { manipulação } \\
\text { controlada da } \\
\text { oferta de } \\
\text { diplomados }\end{array}$ \\
\hline $\begin{array}{c}\text { Conclusão } \\
\text { quanto ao } \\
\text { problema da } \\
\text { massa }\end{array}$ & $\begin{array}{l}\text { Uma rede diver } \\
\text { superior no seio d }\end{array}$ & $\begin{array}{l}\text { ificada de instituiç } \\
\text { a qual as universid } \\
\text { sua originalidade }\end{array}$ & $\begin{array}{l}\text { ões de ensino } \\
\text { ades conservam }\end{array}$ & $\begin{array}{c}\text { Uma rede oficial } \\
\text { uniforme para a } \\
\text { massa e a elite }\end{array}$ & $\begin{array}{l}\text { Adaptação do } \\
\text { número às } \\
\text { necessidades da } \\
\text { economia e } \\
\text { diversificação } \\
\text { das instituições }\end{array}$ \\
\hline
\end{tabular}

Adaptado de Drèze \& Debelle (1983, p. 29).

Por fim, a universidade soviética, sob influência do marxismo-leninismo, foi definida tendo por objetivo a construção da sociedade comunista, segundo as diretrizes aprovadas pelo Conselho de Ministros, em 1961. O ensino é dirigido basicamente para a formação de um quadro de especialistas profissionais, por meio de conhecimentos científicos e políticos para a população, a começar pelos estudantes e mediante a determinação de cotas para os quadros profissionais. Em resumo, a concepção universitária russa visa integrar a instituição ao processo socioeconômico da nação, orientando e reorientando os conteúdos de acordo com os objetivos estabelecidos pelo governo central (DRÈZE \& DEBELLE, 1983).

Em alguma medida, pode-se notar que a concepção de universidade guarda relação com a dinâmica socioeconômica da sociedade, bem como com orientações político-ideológicas do governo e do Estado. No caso brasileiro, sabemos que desde a proclamação da república, os governos buscaram a modernidade como ideal a ser alcançado, a qual, do ponto de vista econômico, coincide com o capitalismo. Em seus primeiros anos de vida, a república não via necessidade de se instalar uma universidade no país, por considera-la algo atrasado, herança do antigo regime. Só em 1920 é que vai surgir a primeira universidade oficial, a Universidade do Rio de Janeiro, atual Universidade Federal do Rio de Janeiro (TORGAL, ÉSTHER, 2014). 
As diretrizes oficiais, especialmente a partir de 1968, seguem as recomendações formuladas no âmbito dos acordos MEC/USAID, cuja orientação fundamental é o estabelecimento da universidade como instrumento de formação de mão de obra para sustentar o emergente modelo capitalista brasileiro. Esta passa a ser a identidade institucional desejada, que vai ser buscada e sustentada, a despeito das iniciativas e experiências contrárias à orientação oficial, como a própria USP, mas especialmente a Universidade do Distrito Federal criada por Anísio Teixeira nos primórdios do Estado Novo de Vargas - e a Universidade de Brasília (1961) - segundo as proposições de Anísio Teixeira e Darcy Ribeiro -, tomada e reformulada pelos governos militares a partir de 1964..Também durante o período entre o Estado Novo e a ditadura militar, o desenvolvimentismo do Presidente JK privilegiou a universidade apenas enquanto formadora de mão de obra especializada para o parque industrial que vinha sendo e viria a ser construído, emblematicamente representado pela indústria automobilística. Ao longo de todo o período militar, a expansão do ensino superior de dá no setor privado, enquanto a universidade pública recebe investimento mais voltados para a pós-graduação (TORGAL, ÉSTHER, 2014).

Do ponto de vista educacional, a situação não se modifica com a queda da ditadura (1985). De certo modo, o modelo capitalista é aprofundado a partir da reforma do Estado, promovido no período do governo de Fernando Henrique Cardoso (1995-2002), algo favorecido pela abertura econômica promovida por seu antecessor, o Presidente Fernando Collor de Mello (sucedido por Itamar Franco em função de seu processo de impeachment). O gerencialismo é implementado nas esferas governamentais e nos aparelhos do Estado, ainda que de maneira não uniforme nem linear. A despeito das resistências da comunidade acadêmica, a universidade é submetida a uma nova lógica, baseada na avaliação de desempenho, a partir de metas de qualidade a serem alcançadas. Neste momento, as avaliações de curso são o símbolo fundamental da política do ensino superior, especialmente por meio de provas realizadas pelos estudantes, o chamado "provão". O gerencialismo, no caso brasileiro, representa a materialização dos princípios da chamada "Nova Gestão Pública", cujos modelos norte-americano e inglês (dos governos Reagan e Thatcher, respectivamente) são a referência fundamental.

Nos mandatos do governo Lula, a política educacional foi modificada, recuperando-se o investimento na universidade e adotando-se políticas sociais de expansão de acesso e permanência, tais como o PROUNI e o REUNI, além das políticas de cotas para ingresso, o programa "Ciência sem fronteiras", por exemplo. No entanto, a lógica do gerencialismo não foi totalmente abandonada. Em grande medida, sua lógica de eficiência e de resultados foi mantida, até porque, a despeito dos investimentos em programas sociais, o modelo econômico capitalismo é mantido e reproduzido, passando-se a admitir, inclusive, que a universidade deve exercer o papel de agente de desenvolvimento. Neste aspecto, a ANDIFES passa a defender este ideal, sob a ótica do modelo da "universidade empreendedora", o que será discutido adiante.

Embora o foco desta discussão seja a universidade brasileira, é fato que a questão educacional ultrapassa as fronteiras nacionais. Neste sentido, tal como no Brasil, a universidade passa a ser vista como passando uma forte crise. No nosso modo de ver, para além da alegada crise fiscal dos países, decorrente do modelo de bem estar social, podemos considerar que a reestruturação produtiva, cujo ápice talvez seja melhor percebido na década de 1990, provoca mudanças profundas na estrutura econômica e, por conseguinte, nas políticas públicas. Neste contexto, Boaventura Santos aponta o que para ele representa, naquele momento, as três crises principais que a universidade experimentava. 
Segundo Santos (2004), as crises são expressões, respectivamente, de três contradições. A primeira se dá entre conhecimentos exemplares e conhecimentos funcionais, que se manifesta na crise de hegemonia, a qual ocorre sempre que uma dada condição social deixa de ser considerada necessária, única e exclusiva.

De um lado, a produção de alta cultura, pensamento crítico e conhecimentos exemplares, científicos e humanistas, necessários à formação das elites de que a universidade se tinha vindo a ocupar desde a Idade Média europeia. Do outro, a produção de padrões culturais médios e de conhecimentos instrumentais, úteis na formação de mão de obra qualificada exigida pelo desenvolvimento capitalista" $(2004$, p. 8). [...] Ao deixar de ser a única instituição no domínio do ensino superior e na produção de pesquisa, a universidade entrara em crise de hegemonia (SANTOS, 2004, p. 9).

Tal crise decorre da incapacidade da universidade em desempenhar funções contraditórias, o que leva os grupos sociais mais atingidos pelo seu déficit funcional, ou o Estado em nome destes, a buscarem alternativas para atingir seus objetivos (SANTOS, 2004). De certo modo, isto explicaria, em parte, a ação estatal oscilar entre investir no setor público e estimular o público.

A segunda contradição se dá entre a hierarquização dos saberes especializados por meio das restrições de acesso e do credenciamento das competências, de um lado, e as pressões sociais e políticas de democratização da instituição e da igualdade de oportunidades para os filhos das classes menos favorecidas, de outro. Tal contradição se manifesta como uma crise de legitimidade, observada à medida que se torna visível socialmente a falência dos objetivos coletivos, ou seja, ela se manifesta sempre que uma dada condição social deixa de ser aceita de forma consensual (SANTOS, 2004).

A terceira contradição se dá entre a autonomia institucional e a produtividade social, manifestando-se na forma de uma crise institucional, que ocorre quando uma dada condição social estável e autossustentada não garante mais os pressupostos que asseguram sua reprodução. A crise ocorre à medida que a especificidade administrativa da instituição é posta em xeque e se lhe impõem outros modelos tidos como mais eficientes, baseados em critérios de eficácia de natureza empresarial ou de responsabilidade social (SANTOS, 2004).

Segundo Santos, a crise institucional prevaleceu sobre as demais, devendo-se a uma pluralidade de fatores, evidenciando-se o desinvestimento do Estado e a globalização mercantil da universidade. A autonomia científica e pedagógica da universidade é baseada na dependência financeira do Estado. Enquanto a instituição e seus serviços eram considerados um bem público, o Estado assegurou seu funcionamento sem maiores conflitos, porém, quando o Estado decidiu reduzir seu compromisso com as universidades e a educação em geral, tornando-os bens públicos não exclusivos garantidos pelo Estado, a universidade entrou em crise institucional. Nos últimos trinta anos, as universidades, na grande maioria dos países, foram atingidas por uma crise institucional, decorrente da perda de prioridade do bem público universitário nas políticas públicas e da consequente descapitalização e redução dos recursos financeiros (SANTOS, 2004).

Ainda segundo o autor, a perspectiva neoliberal considera que as contradições e dilemas das universidades são insuperáveis e que a instituição é, portanto, irreformável, o que acarretou a criação de um mercado educacional universitário global, assumindo-se que a lógica empresarial é 
mais eficiente e capaz de dar conta das demandas sociais e dos problemas gerados pelo modelo universitário tradicional (SANTOS, 2004).

É possível afirmar que a universidade tipo mercantil tem ganhado espaço em todos os continentes, e tal fenômeno vem ocorrendo pelo menos desde a década de 1990, com o avanço da globalização. Cowen (2002, p.35) entende que a universidade vive tanto crises aparentes quanto reais. Para ele, o mundo vivia uma crise real que envolvia (no início dos anos 2000) "um momento de mudança histórica [em que] as estruturas culturais de sustentação educacional, forças econômicas e ideológicas políticas estão mudando muito rapidamente e construindo algo novo".

Torgal (2008), por sua vez, afirma que a universidade contemporânea atua em meio a dicotomia tradição-modernidade. $O$ autor entende que os conceitos permitem significações ambíguas e por vezes contraditórias. Por exemplo, a universidade assume a lógica da modernidade, a qual implica a adoção às regras de mercado, tal como vem sendo apontado. Mas, ao mesmo tempo em que abandona sua lógica tradicional corporativa, não se abandonam suas tradições, que servem para rentabilizar sua atuação.

Embora se referindo à universidade europeia, Cowen (2002) afirma que as universidades passam por três mudanças profundas e fundamentais: sua estrutura cultural, sua relação com o Estado, e sua gestão. Em relação à sua estrutura cultural, cada vez mais a educação deixa de ser concebida como finita e encerrada quando da obtenção de determinado grau acadêmico, passando a ser vista como um processo sem fim, permanente, com diversas implicações para sua estrutura e dinâmica internas. A relação com o Estado - fundamental no contexto da administração política - também se altera, à medida que mais pessoas, portanto, requerem acesso às universidades, o que encarece os investimentos públicos. Como os Estados entendem - ou supõem - que se vive uma economia do conhecimento, a universidade continua a ter importância, mas sua atuação exige esforços "para vincular firmemente as universidades à indústria; para buscar novas formas de integração entre as universidades e a capacidade produtiva, por exemplo, pela criação de parques da ciência [...], para simplificar e encurtar programas de doutorado e padronizar programas para proporcionar treinamento em técnicas de pesquisa e para medir o desempenho das universidades" (COWEN, 2002, p.38). Consequentemente, sua gestão passa a adotar mecanismos de avaliação, de investimento e de recompensas inspirados no modelo empresarial.

\section{APROFUNDAMENTO DA IDENTIDADE MERCANTIL DA UNIVERSIDADE: DESENVOLVIMENTO ECONÔMICO E CAPITALISMO ACADÊMICO}

Se, de um lado, tal como apontado por Boaventura Santos (SANTOS, 2004), a universidade é irreformável para o neoliberalismo, em função de suas tensões e contradições, de outro, alguns autores, como Burton Clark (CLARK, 1998), têm proposto a transformação da universidade. Em outras palavras, a universidade deve passar a assumir uma outra identidade institucional, a identidade empreendedora. Nestes termos, a universidade passa a ser um agente econômico que empreende, cuja finalidade é reagir à dinâmica do mercado e, ao mesmo tempo, buscar inovações úteis para o mercado. Vejamos suas características.

Universidade empreendedora (Entrepreneurial University) é a expressão consagrada por Burton Clark (CLARK, 1998) para nomear o que ele considera um sistema social, ou seja, a 
universidade como um todo, seus departamentos, centros de pesquisa, faculdades e escolas, cuja configuração, em forma de empreendimento ou "empresa" (enterprise), requer esforço e energia e muitas atividades. Sua proposta é que a universidade transforme sua identidade de forma a obter uma postura mais promissora para o futuro, ou seja, as universidades devem se tornar atores significativos e firmes em sua atuação. Ainda segundo o autor, o empreendedorismo institucional pode ser visto tanto como processo como resultado (CLARK, 1998).

Em seu modelo, a universidade empreendedora deve possuir cinco características caminhos fundamentais para se transformar (Pathways of transformation): Núcleo Diretivo Fortalecido (The Strengthened Steering Core), Periferia de Desenvolvimento Expandida (The Expanded Developmental Periphery), Base Diversificada de Financiamento (The Diversified Funding Base), Comunidade Acadêmica Estimulada (The Stimulated Academic Heartland), e Cultura Empreendedora Integrada (The Integrated Entrepreneurial Culture).

No nosso modo de ver, o núcleo gerencial fortalecido sintetiza a identidade institucional proposta, pois ele necessita do envolvimento tanto da administração central quanto dos departamentos acadêmicos. Segundo Clark (1998, p.6), isto "deve reconciliar novos valores gerenciais com os valores acadêmicos tradicionais". Em outras palavras, o autor propõe a adoção de valores empresariais para a universidade. Sua proposta fica clara quando descreve as demais características, as quais, resumidamente, podem ser vistas no Quadro 2, a seguir.

Quadro 2 - Características da universidade empreendedora

\begin{tabular}{|c|c|}
\hline Elementos & Descrição \\
\hline $\begin{array}{l}\text { Núcleo Diretivo } \\
\text { Fortalecido }\end{array}$ & $\begin{array}{l}\text { Implica criar e reforçar o hábito de forte direcionamento (Strenghened steering); tornar a } \\
\text { universidade mais rápida, mais flexível, e, especialmente, mais focada em reações a demandas } \\
\text { crescentes e mutáveis; devem ser organizadas de modo a se reprogramarem em termos de suas } \\
\text { capacidades. }\end{array}$ \\
\hline $\begin{array}{l}\text { Periferia de } \\
\text { Desenvolvimento } \\
\text { Expandida }\end{array}$ & $\begin{array}{l}\text { Envolve a existência de unidades periféricas tais como escritórios de extensão profissionalizados } \\
\text { que trabalham na transferência de conhecimentos, contato com a indústria, desenvolvimento } \\
\text { de propriedade intelectual, educação continuada, captação de recursos e até mesmo no } \\
\text { relacionamento com ex-alunos. Os departamentos tradicionais continuam importantes, mas } \\
\text { centros de pesquisa não disciplinares implicam a possibilidade de levar para dentro da } \\
\text { universidade orientações de projetos oriundos de fora que estão envolvidos seriamente em } \\
\text { resolver problemas cruciais para o desenvolvimento social e econômico. Tais centros fazem a } \\
\text { mediação dos departamentos com o mundo exterior. }\end{array}$ \\
\hline $\begin{array}{l}\text { Base de } \\
\text { Financiamento } \\
\text { Diversificada }\end{array}$ & $\begin{array}{l}\text { As universidades devem se valer de } 3 \text { fontes principais de financiamento: governamental; } \\
\text { conselhos de pesquisa (no Brasil, seriam as agências de fomento à pesquisa), por meio de bolsas } \\
\text { e contratos; e um vasto e profundo portfólio de fontes de financiamento da indústria, governos } \\
\text { locais e fundações filantrópicas, royalties de propriedade intelectual, receitas de serviços do } \\
\text { campus, taxas estudantis e contribuições de ex-alunos. O objetivo é obter maior autonomia à } \\
\text { medida que não se depende de uma única fonte de financiamento. }\end{array}$ \\
\hline $\begin{array}{l}\text { Comunidade } \\
\text { Acadêmica } \\
\text { Estimulada }\end{array}$ & $\begin{array}{l}\text { É na comunidade acadêmica que os valores acadêmicos estão fortemente enraizados. Neste } \\
\text { nível, os valores acadêmicos tradicionais devem se misturar aos valores gerenciais. Na } \\
\text { universidade empreendedora, o meio acadêmico aceita um sistema de crenças transformado. }\end{array}$ \\
\hline $\begin{array}{l}\text { Cultura } \\
\text { Empreendedora } \\
\text { Integrada }\end{array}$ & $\begin{array}{l}\text { Universidades Empreendedoras, tal como empresas da indústria de alta tecnologia, adotam } \\
\text { uma cultura que envolve mudança. Essa nova cultura pode iniciar-se como uma ideia } \\
\text { institucional relativamente simples sobre mudança que, mais tarde, se consubstancia em um } \\
\text { conjunto de crenças, as quais, se difundidas na comunidade acadêmica da instituição, se } \\
\text { transformam em uma cultura universitária. Culturas robustas estão enraizadas em práticas } \\
\text { robustas. Conforme ideias e práticas interagem, o lado simbólico ou cultural das universidades } \\
\text { se torna particularmente importante na busca por cultivar uma identidade institucional e uma } \\
\text { reputação distinta. }\end{array}$ \\
\hline
\end{tabular}

Baseado em Clark (1998). 
De modo a demonstrar seus argumentos, Clark descreve os casos das universidades de Warwick na Inglaterra, Twente na Holanda, Strathclyde na Escócia, Chalmers na Suécia, e Joensuu na Finlândia. Como se pode perceber no Quadro 2, a proposta tem como base o modelo competitivo de economia e de mercado, em que cabe ao Estado financiar parte das atividades da universidade, ao mesmo tempo em que a ela atribui um papel de agente facilitador do desenvolvimento econômico, à medida que prestaria determinados serviços à sociedade.

A despeito da influência de seu modelo, a formulação de Clark também recebeu críticas significativas, como no caso de lan Finlay, funcionário da Faculdade de Educação da Universidade de Strathclyde. Sua crítica reside, fundamentalmente, na metodologia de Clark, que teria entrevistado uma quantidade mínima de indivíduos e apenas aqueles que seriam favoráveis à sua proposta. Dentre os problemas de implantação, estaria, por exemplo, a possibilidade de criação de uma cultura organizacional única e homogênea (FINLAY, 2004).

O argumento central para a defesa da universidade empreendedora é seu papel enquanto promotor do desenvolvimento econômico, especialmente local e regional. Levine (2009) relativiza este argumento ao mostrar, por meio de uma pesquisa realizada nos Estados Unidos, envolvendo suas 55 maiores regiões, que não há correlações significativas entre atividades da universidade empreendedora (como patentes, licenças, gastos com pesquisas) e os indicadores principais de bem estar econômico local e regional. Segundo o autor, mesmo tomando-se casos exemplares, como a Johns Hopkins University e a Yale University, os dados mostram que mesmo "universidades classe mundial não são necessárias nem suficientes para promover o desenvolvimento econômico" (LEVINE, 2009, p.4). Segundo o autor, à universidade tem sido atribuído um papel muito além dos reais impactos que ela pode promover, enquanto o chamado "capitalismo acadêmico" dirige a universidade orientado para o mercado em direção ao processo produtivo como a contribuição primária da universidade para o desenvolvimento econômico.

Para Levine (2009, p.10), o modelo de universidade empreendedora está baseado no amálgama de três teorias de desenvolvimento econômico:

1 - "Teoria do crescimento endógeno", a qual sustenta que o estoque de conhecimento e inovação tecnológica são os determinantes-chave da taxa de crescimento econômico; que ideias e mudança tecnológica produzem retornos crescentes (e não decrescentes, como afirma a teoria econômica clássica) [...];

2 - "Teoria da Competitividade", popularizada por Michael Porter, segundo a qual a prosperidade regional flui da vantagem competitiva estabelecida para firmas locais em determinados clusters [...];

3 - "Triunfo do Mercado", segundo a qual a universidade se torna parte de uma cultura "tudo à venda" [...]; e, citando, literalmente, Slaughter e Rhoades (2004, p.29) a universidade foca "o conhecimento menos como um bem público do que como uma commodity a ser capitalizada em atividades orientadas para o lucro".

Nos termos de Rhoades e Slaughter (2004, p.37), as universidades públicas estariam aderindo ao que eles chamam de "capitalismo acadêmico", isto é, as "instituições de ensino superior estão buscando gerar receitas a partir de suas funções centrais de educação, de pesquisa e de serviços, desde a produção de conhecimentos (tais como pesquisas que levem a patentes) gerados pelas faculdades até o currículo da faculdade (materiais de ensino que possam ter 
copyright e serem comercializados)". Tal como Santos (2004), os autores consideram que a universidade deixa de priorizar o conhecimento como bem público, passando a trat;a-lo como uma mercadoria comercializável, o que eles chamaram de cultura "tudo à venda".

Ainda segundo Levine (2009), a orientação da universidade para o mercado que se consubstancia na parceria entre a universidade, a indústria e o governo, chamado por alguns autores como o modelo da Tripla Hélice (cf. ETZKOWITZ, 2006), parece mais um mero rótulo do que uma rigorosa articulação entre teoria de universidades e desenvolvimento econômico.

Alguns autores têm buscado formas de justificar e de explicar a transformação da universidade em direção à vertente mercantil e empreendedora, a partir de algumas variáveis. Maasen e Olsen ' (citados por BALBACHEVSKY, KERBAUY, FABIANO, 2013), por exemplo, articulam o grau de compartilhamento com as normas e objetivos da universidade com as fontes da dinâmica institucional, conforme se pode observar no Quadro 2.

A partir da matriz de tipos ideais de Maasen e Olson (2007 Balbachevsky, Kerbauy, Fabiano (2013) entendem que a universidade brasileira se configura, na realidade, como um híbrido do modelo político e do modelo de instrumento de política nacional. No nosso modo de ver, os tipos ideais propostos, embora funcionem como recursos metodológicos, articulam posições extremas, o que pode sugerir que, na prática, as instituições devam aderir a um deles.

No entanto, da forma como a tipologia é descrita, ela apresenta duas fragilidades substanciais: não considera as finalidades da universidade; e os modelos são descontextualizados historicamente. Como a finalidade da universidade não é discutida, admitimos que, ou ela é pressuposta mas não sabemos qual é, ou ela é absolutamente desconsiderada. No primeiro caso, supõe-se que a finalidade é um dos elementos definidos internamente ou externamente. No segundo caso, supõe-se que ela é irrelevante. No nosso modo de ver, este pode ser um raciocínio falacioso, na medida em que, embora sejam tipos ideais, na prática, a configuração que a universidade assume é uma espécie de mistura de todos os modelos; certas dinâmicas são definidas internamente, enquanto outras o são a partir de relações externas. Assim, podemos ser levados a pensar que os problemas da universidade estejam apenas no modelo, e de um ponto de vista meramente operacional.

Quadro 3 - Tipologia de governança universitária

\begin{tabular}{|c|c|c|}
\hline & $\begin{array}{c}\text { Dinâmicas institucionais determinadas } \\
\text { por fatores internos }\end{array}$ & $\begin{array}{c}\text { Dinâmicas institucionais determinadas } \\
\text { por fatores externos }\end{array}$ \\
\hline $\begin{array}{l}\text { Atores internos } \\
\text { compartilham } \\
\text { normas e objetivos }\end{array}$ & $\begin{array}{l}\text { Modelo humboldtiano: governo de } \\
\text { pares } \\
\text { Lógica: identidade } \\
\text { Critério de avaliação (qualidade): } \\
\text { qualidade científica } \\
\text { Dinâmica: comunidade científica }\end{array}$ & $\begin{array}{c}\text { Modelo: Universidade como instrumento } \\
\text { de política nacional } \\
\text { Lógica: administrativa } \\
\text { Critério de avaliação (qualidade): } \\
\text { resultado político } \\
\text { Dinâmica: decisões governamentais }\end{array}$ \\
\hline $\begin{array}{l}\text { Atores têm } \\
\text { percepções } \\
\text { conflitivas sobre } \\
\text { normas e objetivos }\end{array}$ & $\begin{array}{l}\text { Modelo político: Representação de } \\
\text { interesses } \\
\text { Lógica: representação } \\
\text { Qualidade: acomodação de interesses } \\
\text { Dinâmica: barganha interna }\end{array}$ & $\begin{array}{c}\text { Modelo: Empresa de serviços operando } \\
\text { em mercados competitivos } \\
\text { Lógica: competição } \\
\text { Qualidade: responsividade } \\
\text { Dinâmica: respostas à pressões } \\
\text { competitivas }\end{array}$ \\
\hline
\end{tabular}

Fonte: Maasen e Olsen (2007) apud Balbachevsky, Kerbauy, Fabiano (2013) (adaptado) 
Neste sentido, entendemos que a tipologia de Drèze e Debelle (1983) é mais precisa e adequada à compreensão da universidade. Os autores consideram que as três primeiras do quadro 1 (I, II e III) possuem sua dinâmica estabelecida a partir de normas internas próprias, enquanto as demais (IV e V) têm suas normas a partir do exterior, cujos propósitos sociopolíticos e socioeconômicos são evidentes. No entanto, o que está em jogo é sua finalidade. Por outro lado, esta é resultado de um forte e interminável jogo de poder. A ausência ou a omissão da finalidade da universidade na tipologia de Maasen e Olsen sugere que tratam-se de opções dentro de um cardápio, sem uma devida contextualização e um enquadramento político-histórico, de acordo com as ideologias em jogo e em disputa. Sua tipologia parece estar desconectada do modelo de sociedade que se busca num dado estágio de desenvolvimento desta sociedade. Isto não implica dizer que haja sempre um único modelo de sociedade. Ao contrário, é neste sentido que as disputas ideológicas tomam lugar, envolvendo as relações entre economia, governo, Estado e sociedade. A estrutura e a dinâmica da relação entre a universidade e o Estado (governo) serão decorrentes destas disputas, em que atores sociais possuem posições desiguais e desequilibradas no jogo de poder.

Se admitirmos, pelo menos hipoteticamente, que haja um amplo acordo entre governo, Estado e sociedade quanto à finalidade da universidade, provavelmente seu tipo será único (em sua lógica mais geral), não havendo espaço para modelos concorrentes. Por outro lado, se a universidade está em crise, e se esta crise é expressão de uma crise mais ampla, modelos concorrentes e conflitantes emergem, a partir das concepções dos atores sociais. Do ponto de vista da governança, a universidade se torna terreno de disputa entre as demandas internas e demandas externas (Quadro 4). O resultado, tanto em termos da concepção quanto do modelo de governança, dependeria da relação de poder entre os atores envolvidos.

Quadro 4-As narrativas conceituais acerca da universidade brasileira segundo atores sociais

\begin{tabular}{|c|c|}
\hline Atores sociais & Concepção de universidade \\
\hline $\begin{array}{c}\text { MEC/SESu } \\
\text { (Ministério da Educação/Secretaria de } \\
\text { Educação Superior) }\end{array}$ & $\begin{array}{c}\text { Universidade como agente de desenvolvimento econômico e } \\
\text { competitividade internacional. Constitui a concepção oficial } \\
\text { governamental. Universidade como formadora de quadros } \\
\text { profissionais para o mercado de trabalho. }\end{array}$ \\
\hline $\begin{array}{c}\text { ANDIFES } \\
\text { (Associação Nacional dos Dirigentes das } \\
\text { Instituições Federais de Ensino Superior) }\end{array}$ & $\begin{array}{l}\text { Universidade empreendedora para o desenvolvimento econômico } \\
\text { e competitividade internacional. Compatível com a concepção } \\
\text { oficial. }\end{array}$ \\
\hline $\begin{array}{c}\text { UNE } \\
\text { (União Nacional dos Estudantes) }\end{array}$ & $\begin{array}{c}\text { Universidade para o desenvolvimento econômico e } \\
\text { competitividade internacional. Compatível com a concepção } \\
\text { oficial. }\end{array}$ \\
\hline $\begin{array}{c}\text { PROIFES } \\
\text { (Federação de Sindicatos de Professores de } \\
\text { Instituições Federais de Ensino Superior) }\end{array}$ & \multirow{3}{*}{ Universidade pública, gratuita, laica, desinteressada e autônoma. } \\
\hline $\begin{array}{c}\text { ANDES - SN } \\
\text { (Sindicato Nacional dos Docentes das } \\
\text { Instituições de Ensino Superior) }\end{array}$ & \\
\hline $\begin{array}{c}\text { FASUBRA } \\
\text { (Federação dos Sindicatos de Trabalhadores } \\
\text { das Universidades Brasileiras) }\end{array}$ & \\
\hline $\begin{array}{c}\text { ANEL } \\
\text { (Assembleia Nacional de Estudantes - Livre) }\end{array}$ & $\begin{array}{l}\text { Universidade pública, autônoma, laica, gratuita, de qualidade que } \\
\text { produza conhecimento a serviço dos trabalhadores. }\end{array}$ \\
\hline
\end{tabular}

Fonte: Ésther (2015, p.213) 
Se Boaventura Santos está correto quando diagnostica as crises da universidade - aliás, diversos autores o fazem, inclusive no Brasil -, então somos capazes de compreender os conflitos entre os atores sociais e com a sociedade num sentido amplo. Mas, no jogo de poder, o modelo mercantil ou empreendedor de universidade tem sido amplamente difundido e aceito como modelo a ser adotado no mundo e no país, a despeito das críticas e resistências, pelas próprias instituições, ou, na melhor das hipóteses, por sua representação política, a ANDIFES. Uma visita em seu site institucional mostra a existência de uma comissão de reitores estabelecida para

difundir a cultura do empreendedorismo no âmbito das IFES e definir e implantar políticas, programas e ações institucionais que visem aplicar os seus princípios nos programas de formação, geração e aplicação de conhecimento e responsabilidade social das universidades adensando a sua atuação como agente de desenvolvimento social, cultural e econômico (ANDIFES, 2014).

Ao que tudo indica, trata-se do antigo ideal brasileiro de adentrar a modernidade, deixando para trás o tradicional e o antigo, agora travestido de adentrar a "Era do conhecimento". Neste contexto, o modelo empreendedor de universidade, notadamente baseado na realidade das universidades e do contexto econômico norte-americano, tem sido saudada como sinal de modernidade e de referência para a universidade brasileira, a despeito de todas as críticas. Mas, será este um caminho inexorável?

\section{RUMOS E DESAFIOS DA UNIVERSIDADE CONTEMPOÂNEA}

A crítica ao modelo mercantil da universidade tem sido recorrente também entre autores brasileiros. Dentre eles, destacamos a crítica de Chauí, para quem a universidade tem desempenhado o papel indesejado mas necessário à sua sobrevivência, de

criar incompetentes sociais e políticos, realizar com a cultura o que a empresa realiza com o trabalho, isto é, parcelar, fragmentar, limitar o conhecimento e impedir o pensamento, de modo a bloquear toda tentativa concreta de decisão, controle e participação, tanto no plano da produção material quanto no da produção intelectual. Se a universidade brasileira está em crise é simplesmente porque a reforma do ensino inverteu seu sentido e finalidade - em lugar de criar elites dirigentes, está destinada a adestrar mão de obra dócil para um mercado sempre incerto. E ela própria ainda não se sente bem treinada para isto, donde sua "crise" (CHAUÍ, 2001, p.46).

Assim, tem prevalecido o que a autora chama de discurso "competente", ou seja, o discurso instituído - que é aquele que pode ser proferido, ouvido e tomado como verdadeiro (CHAUÍ, 2006) - que faz prevalecer os preceitos da teoria do capital humano em detrimento dos preceitos da teoria da emancipação humana (SEVERINO, 2008).

Neste sentido, Honneth (2013) faz uma análise muito interessante ao demonstrar como a relação entre Estado e educação desapareceu no contexto da filosofia política. Desde Kant, a relação entre ambos - a arte do governo e a arte da educação - era fundamental na vida social, de modo a levar a criança ainda submissa a um estado de maturidade e de liberdade. Nas palavras de Honneth (2013, p.546), 
O ser humano pequeno e impelido pela natureza precisa percorrer primeiro um processo de educação voltada para a liberdade para poder se tornar membro do povo de um Estado que governa a si mesmo, assim como, inversamente, só cidadãos e cidadãs autônomos podem institucionalizar uma educação pública que possibilite a seus filhos o caminho para a maioridade política. Por isso, uma boa educação e uma ordem estatal republicana dependem complementarmente uma da outra, porque a boa educação produz concretamente, por meio de uma instrução geral e pública, as capacitações culturais e morais com cuja ordem estatal republicana pode prosperar de tal maneira que a cidadania ainda participe da emancipação política também dos integrantes das classes mais baixas.

Tal vínculo entre uma teoria de educação e uma teoria da democracia se perdeu, cujas razões não cabe apontar aqui. Mas, segundo Honneth (2013), podemos alegar que junto com o entorno social e econômico, as demandas feitas à escola também se modificaram, o que tem levado à predominância de uma razão econômica que preconiza um sistema escolar no qual o estudante é inserido para a "aquisição de capacidades aproveitáveis do ponto de vista puramente econômico" (p.557)

Assim, nos dias de hoje, a escola tem preconizado a formação da autonomia individual, contrariamente ao que defendiam Durkheim e Dewey - como Kant -, segundo os quais a educação deveria se caracterizar pela "ideia de ensinar aos alunos uma percepção certeira do que significa entender o colega como um parceiro com direitos iguais num processo comum de aprendizado e investigação" [...] de modo que a "escola pública volte a gerar em cada nova geração as formas de comportamento que são vitalmente necessárias para a formação da vontade democrática" (HONNETH, 2013, p.556). Tal era o modelo de sociedade até o fim do nacional-socialismo, na era moderna, segundo o autor.

Como se pode perceber, a educação formal (em todos os níveis) tem sido realizada de forma descolada de um modelo de sociedade que preconiza a democracia como valor e como forma de existência. Por outro lado, é exatamente em seu nome que a orientação neoliberal defende o modelo escolar atual, especialmente no caso da universidade, tanto em termos de sua concepção mercantil e empresarial, que visa a formação de recursos humanos para a esfera da produção - principalmente privada - quanto de seu modelo de governança baseada nas demandas externas - entendidas como as demandas do mercado - e na lógica competitiva, por recursos e de resultados.

\section{CONSIDERAÇÕES FINAIS}

Neste ensaio, levantamos algumas questões acerca da universidade, sobretudo algumas tensões fundamentais, relativas a seu papel no sociedade contemporânea. Neste contexto, a relação da universidade com a esfera estatal e governamental é crítica, na medida em que esta, pelo menos a princípio, constitui-se como elemento ordenador de sua atuação.

Atualmente, observamos o avanço do modelo mercantil, empresarial ou empreendedor da universidade em todos os continentes, associado a um modelo econômico e político de cariz neoliberal, para quem a universidade deve ser uma espécie de "motor de desenvolvimento" (LEVINE, 2009), dentro do espírito do capitalismo acadêmico. Assim, no nosso modo de ver, a universidade tem se aproximado de outros modelos organizacionais, tais como uma universidade 
corporativa ou um centro de pesquisa e desenvolvimento, ou, ainda, conforme Cowen (2002), uma corporação de conhecimento, todas voltadas para a promoção do desenvolvimento econômico e para a transferência de tecnologia para o setor privado. Por outro lado, como bem apontou Honneth (2013), em todas as pesquisas comparativas internacionais, são os países que adotaram os ideais democráticos que alcançaram os melhores resultados, como é o caso emblemático da Finlândia. Neste caso, o papel do Estado e sua relação com o sistema escolar é fundamental.

O Brasil tem sido marcado por uma trajetória marcante de autoritarismo, a despeito de todas as tentativas de se estabelecer uma sociedade mais justa, democrática e igualitária. Infelizmente, o recente impedimento da Presidente Dilma Rousseff mostrou que ainda estamos longe de tal ideal, embora não possamos afirmar que seu governo procurou estabelecer o nexo entre educação e democracia, tal qual nos termos analisados por Honneth (2013).

Portanto, entendemos que discutir a universidade passa por discutir sua finalidade e razão de existência, ou, em outras palavras, qual universidade para qual sociedade.

\section{REFERÊNCIAS}

1. ANDIFES. Associação Nacional dos Dirigentes das Instituições de Ensino Superior [2014]. Comissões. Empreendedorismo. (2012). Disponível em http://www.andifes.org.br/?page _id=1300. Acesso em 05 mar. 2014.

2. BALBACHEVSKY, E., KERBAUY, M. T., FABIANO, N. L. A Governança universitária em transformação: a experiência das universidades públicas brasileiras [2013]. Disponível em http://nupps.usp.br/downloads/relatorio2013/Anexo_09_Balbachevsky_A\%20Governan \%C3\%A7a\%20universit\%C3\%A1ria\%20em\%20transforma\%C3\%A7_o.pdf. Acesso em 10 abr. 2016.

3. CHAUÍ, M. Cultura e democracia: o discurso competente e outras falas. São Paulo: Cortez, 2006.

4. CHAUÍ, M. Escritos sobre a universidade. São Paulo: Unesp, 2001.

5. CLARK, B. Creating entrepreneurial universities. Oxford: Pergamon, 1998.

6. COWEN, R. A crise da Universidade: uma nota comparativa sobre gestão e uma observação para o Brasil. Em aberto, 19(75), pp. 35-48, 2002.

7. DRÈZE, Jacques, DEBELLE, Jean. Concepções da universidade. Fortaleza: Edições Universidade Federal do Ceará, 1983.

8. ÉSTHER, A. B. Que universidade? Reflexões sobre a trajetória, identidade e perspectivas da universidade pública brasileira. Espacio, Tiempo y Educación, v. 2, n. 2, julio-diciembre pp. 197221, 2015.

9. ETZKOWITZ, H. Triple Helix twins: innovation and Sustainability. Science and Public Policy, 1(33), pp. 64-77, 2006.

10. FINLAY, I. Living in an "entrepreneurial" university. Research in Post-Compulsory Education, 9(3), pp. 417-433, 2004.

11. HONNETH, Axel.Educação e esfera pública democrática: um capítulo negligenciado da filosofia política. Civitas, v.13, n.3, p.544-562, 2013. 
12. LEVINE, Marc. V. The false promise of the entrepreneurial university: selling academic commercialism as an "engine" of economic development in Milwaukee. University of Wisconsin-Milwaukee. Center for Economic Development. Working Paper, September, 2009.

13. RHOADES, G., SLAUGHTER, S. Academic capitalism in the new economy: challenges and choices. American Academic, 1(1), pp. 37-59, 2004.

14. SANTOS, B. S. A universidade do século XXI: para uma reforma democrática e emancipatória da Universidade. São Paulo: Cortez, 2004.

15. SANTOS, B. S. Pela mão de Alice: o social e o político na pós-modernidade. São Paulo: Cortez, 1995.

16. SEVERINO, A. J. O ensino superior brasileiro: novas configurações, velhos desafios. Educar, $n$. 31, pp. 73-89, 2008.

17. TORGAL, L. R. A universidade entre a tradição e a modernidade. Revista Intellectus, ano 7, v. 1, pp. 1-40, 2008

18. TORGAL, L. R., ÉSTHER, A. B. Que universidade? Interrogações sobre os caminhos da universidade em Portugal e no Brasil. Juiz de Fora/Coimbra: EDUFJF/IU, 2014.

\footnotetext{
'Maasen, P. e J. Olsen, J. P."European debates on the knowledge institution: the modernization of the university at the european level" in (ed) University dynamics and European integration. Springer, kindle ed., loc. 87-376.

O autor agradece à Fapemig (APQ 0163/13), cuja pesquisa financiada possibilitou a elaboração deste artigo.
} 